\title{
Tempos midiáticos: passado, presente e futuro em modos narrativos $^{1}$
}

\author{
Marialva Carlos BARBOSA ${ }^{2}$
}

\begin{abstract}
Resumo:
O texto reflete sobre a maneira como o mundo contemporâneo vive a temporalidade, mostrando a emergência do que denominamos tempos midiáticos. Apresenta um balanço das reflexões que realizamos há duas décadas sobre o tema, ou seja, a forma como as narrativas comunicacionais apresentam o passado, o presente e futuro e os laços que estabelecem entre os tempos. Para isso dividimos a reflexão em duas partes: na primeira apresentamos a conceituação de tempos midiáticos e na segunda refletimos sobre o que estamos denominando tramas da temporalidade, procurando caracterizar a maneira como, no mundo contemporâneo, elas se apresentam nas narrativas midiáticas.
\end{abstract}

Palavras-chave: Tempo. Narrativa. Mídia.

\section{Media times: past, presente and future in narrative modes}

\begin{abstract}
:
The text reflects on how the contemporary world lives the temporality, showing the emergence of what we call mediatic times. It presents a balance of the reflections that we made two decades ago about the theme, that is, the way in which the communicative narratives present the past, the present and the future and the ties they establish between the times. For this we divided the reflection in two parts: in the first one we present the conceptualization of mediatic times and in the second one we reflect on what we are calling temporality plots, trying to characterize the way in the contemporary world the temporal plots are presented in the media narratives.
\end{abstract}

Keywords: Times. Narrative. Media.

\section{Tiempos mediáticos: pasado, presente y futuro en modos}

\section{narrativos}

\section{Resumen:}

El texto reflexiona sobre la forma en que el mundo contemporáneo vive la temporalidad, mostrando el surgimiento de lo que llamamos tiempos mediáticos. Presenta un balance de las reflexiones que hicimos hace dos décadas sobre el tema, es decir, la forma en que las narrativas comunicativas presentan el pasado, el presente y el futuro y los lazos que establecen entre los tiempos. Para esto dividimos la reflexión en dos partes: en la primera presentamos la conceptualización de los tiempos mediáticos y en la segunda reflexionamos sobre lo que llamamos tramas de temporalidad, tratando de caracterizar la forma en que, en el mundo contemporáneo, se presentan en las narrativas de los medios.

\footnotetext{
${ }^{1}$ Versão revisada e ampliada da palestra proferida na mesa A mídia e os estratos do tempo no XII Encontro Nacional de História da Mídia, realizado em Natal (RN), em junho de 2019.

${ }^{2}$ Professora do Programa de Pós-Graduação em Comunicação e Cultura da Universidade Federal do Rio de Janeiro. Professora titular de jornalismo da mesma Universidade. Doutora em História (1995-UFF), com pós-doutorado em Comunicação pelo LAIOS-EHESS (Paris, França). E-mail: marialva153@gmail.com.
} 
Palabras clave: Tiempo. Narrativa. Medios de comunicación.

\section{Introdução}

Desde pelo menos a virada do século XX para o XXI, a questão do tempo e da sua relação com os meios de comunicação têm sido objeto de algumas das minhas pesquisas e, sobretudo, de digressões reflexivas. Impactada por uma temporalidade que emergia no século XXI e que apontava, tal como diagnosticou Calvino (1989) nas suas Leçons américaines, para as palavras-chave "rapidez, visibilidade e multiplicidade", em diversos textos (BARBOSA, 1999, 2000a, 2000b, 2003, 2007b, entre outros) caracterizei esse espírito do tempo da nossa época a partir de três expressões: rapidez, velocidade e mudança. Em todas as reflexões, destacava a centralidade dos meios de comunicação e das mídias tanto as tradicionais, pertencentes ainda ao mundo analógico, quanto aquelas que emergiam no mundo digital, produzindo, sobretudo, o mundo como imagem, multiplicando-o em "fantasmagorias de jogos de espelhos", fazendo das imagens "forma e significado", impondo atenção e novos sentidos virtuais (CALVINO, 1989, p. 99-100).

No mesmo cenário de produção de diagnósticos, percebia a centralidade dos meios de comunicação na produção do sentido de aceleração, não apenas por que tornava evidente a compressão do tempo, a partir da transformação da noção de espaço, mas ainda pela multiplicação de artefatos que tornavam possível o consumo de informações na profusão instantânea das telas digitais. Mesmo antes da radicalização desse movimento, como verificamos nos últimos anos, o tempo midiático construía uma nova lógica cultural a partir da multiplicação dos cenários do tempo real, por exemplo, no mundo do jornalismo. Foi preciso, num momento intermediário, divulgar os acontecimentos contemporâneos com a sensação de que se fazia no momento mesmo do desenrolar do fato jornalístico, no que então passou a ser designado tempo real.

Diagnosticava, desde então, a maneira como os meios de comunicação evocam o tempo e que estes eram responsáveis, ao lado de diversas ações fundamentais na fabricação do mundo contemporâneo (a lógica perversa dos mercados financeiros, por exemplo), por uma espécie de banalização do tempo (CHESNEAUX, 1996).

Enfatizava, a partir de então, que, ao lado da exacerbação do olhar sobre o presente, a experiência do tempo contemporânea se caracteriza pelo esfacelamento da articulação entre passado, presente e futuro, o que resulta num regime de historicidade marcado pela "crise do tempo" (HARTOG, 2014). Como enfatiza Hartog (2014), a 
produção do tempo histórico, nesse cenário, parece estar suspensa, o que faz com que a experiência temporal contemporânea seja dominada por um presente perpétuo, um presente "inacessível e quase imóvel que busca, apesar de tudo, produzir para si mesmo o seu próprio tempo histórico" (HARTOG, 2014, p. 39). É como se não houvesse nada além do presente.

Essa particular configuração do tempo, para alguns autores, como Baschet (2001), tem como momento chave o final dos anos 80 do século $\mathrm{XX}$, quando se torna dominante o "presente perpétuo", encobrindo o conhecimento crítico do passado e, ao mesmo tempo, obscurecendo as perspectivas de futuro. O presente perpétuo pressupõe uma nova relação entre o que Koselleck (2006) denomina "campo de experiência" e "horizonte de expectativa", uma vez que o futuro se torna conhecido por antecipação e o passado se inclui de maneira emblemática no presente. Não é que desapareçam as referências ao passado e ao futuro: elas agora são construídas sobre novas bases. Instaura-se nesse presente perpétuo o que denomino tempo passando (BARBOSA, 2017), já que na formulação da maneira como se vive o tempo, centrado no presente absoluto, num mundo sem projeto futuro e no qual só com muito esforço se pode perceber a distinção dos tempos, qualquer instante se transforma em tempos de frenesi que duram continuamente. Nos domínios da cena figura, portanto, o tempo passando.

Há que se considerar, ainda, que a instantaneidade e o imediatismo instauram a ditadura dos tempos breves e dos ritmos sincopados. Cria-se, paradoxalmente, uma espécie de negação do tempo que passou, em que a interdição ao envelhecimento, por exemplo, é apenas um dos seus sintomas. Há a ditadura do presente, na qual se impõe um presente eterno, feito de instantes efêmeros, a partir da ilusão permanente das novidades, substituídas no momento seguinte e numa rapidez estonteante, num cenário no qual o gesto substituível se repete inúmeras vezes. Diz Baschet (2001, p. 69): “o regime do presente perpétuo convém à lógica econômica do mercado e do proveito, e aos discursos amnésicos e míopes que os acompanham". Por outro lado, a rapidez das ações, que se tornam compulsórias nesse novo regime, impede a emergência do futuro como expectativa. O futuro já está contido no presente, de tal forma que o presente perpétuo (ou o tempo passando) não admite projetos futuros.

\section{Tempos midiáticos}

Nesse cenário, então, o que estamos conceituando como tempo, ou melhor, tempos midiáticos? A primeira categorização diz respeito diretamente à experiência do 
tempo vivido na contemporaneidade e que coloca em destaque o ininterrupto. É como se houvesse na arquitetura temporal do mundo hoje um espraiamento dos modos comunicacionais, fazendo com que também do ponto de vista cotidiano se viva o tempo midiático: o do eterno presente, aquele que dilui a fronteira do presente com o futuro, em que o passado quando emerge não tem espessura e, mais do que isso, passa a ser também incluído no presente. A desrealização do tempo, marca fundamental de nossa arquitetura temporal, é a experiência do tempo midiático que se desliza para o tempo da vida.

A segunda refere-se às multiplicidades de articulações temporais que emergem das formulações narrativas dos próprios meios de comunicação. Assim, existe uma maneira dominante de viver o tempo no mundo contemporâneo que espelha as formulações narrativas da mídia, governadas pela lógica do ininterrupto. Mas a própria mídia promove outras articulações temporais nas suas teias narrativas, construindo trânsitos entre passado, presente e futuro. Essas formulações narrativas, que se transformam no curso da história, como veremos brevemente ainda neste texto, caracterizam também o que denomino tempo midiático.

Assim, primeiramente, diante do fluxo de informações e de imagens que frequentam as telas de nosso cotidiano digital, em narrativas fluidas e voláteis, estamos afirmando a conexão entre esses formatos e a maneira como se produz (e se vive) a experiência do tempo. Na profusão de imagens e informações presentes nas telas digitais, o tempo midiático dominante como tempo no mundo da vida apresenta-se marcado, sobretudo, pela aceleração.

Portanto, tempos midiáticos são, simultaneamente, os aspectos dominantes na arquitetura temporal do mundo contemporâneo e a articulação temporal que se deixa ver nas narrativas que emergem dos meios de comunicação e nas quais a relação passado, presente e futuro e os sentidos atribuídos a cada um desses estratos do tempo se fazem a partir de singularidades, que, concomitantemente, aproxima e distancia o momento contemporâneo de outras épocas da história. Dai a opção pelo uso do plural: tempos.

Se a estrutura temporal dos chamados tempos modernos era marcada, por exemplo, pela ideologia do progresso e com ela a construção de uma abertura definitiva em relação ao futuro, onde estaria localizada a redenção, caracterizando-se no dizer de Hartog (2014), pela assimetria entre experiência e expectativa, na contemporaneidade, como remarcamos anteriormente, a experiência parece ser de um presente perpétuo, instaurando um presentismo sem fim. 
Cada momento histórico edifica a sua arquitetura temporal, com formas dominantes de se viver a experiência do tempo e os meios de comunicação constroem suas narrativas em consonância com essa experiência, mas também realimentam continuamente as marcas exponenciais dessa mesma arquitetura. Se o passado é fluido, o presente volátil e no qual estão incluídos um futuro impreciso, as narrativas midiáticas deixam antever nas suas tramas esses jogos articuladores. O sentido efêmero do tempo, por exemplo, que se expressa hoje na descartabilidade da maioria dos objetos consumidos, aparece com vigor na construção simbólico-discursiva dos meios de comunicação (BARBOSA, 2017).

\section{Mídia e trama de temporalidades}

Antes de refletir especificamente sobre as tramas temporais presentes nas narrativas dos meios de comunicação, convém ainda remarcar alguns aspectos em relação ao que estamos denominando experiências temporais. É evidente que coexistem numa mesma sociedade e num mesmo momento diferentes experiências de se viver o e no tempo. Não podemos atribuir a mesma experiência do tempo, de maneira simétrica, aos excluídos, aos que vivem à margem da vida, aos sujeitos dos quais se quer retirar sua condição humana, e aqueles que ocupam lugares de detentores de fala e de poder na sociedade. De um lado, há o tempo dos fluxos, da aceleração e da mobilidade (HARTOG, 2014), e, de outro, há o tempo dos que continuam excluídos pela lógica perversa do capitalismo, em que se vivencia a permanência do transitório, nas relações de precarização do trabalho, o presente sem passado dos deslocados, dos que vivem as múltiplas diásporas sociais e onde não há um futuro, já que o tempo dos projetos nunca esteve aberto para eles.

Portanto, quando falamos da prevalência de uma arquitetura temporal governada pela aceleração, estamos nos referindo a uma experiência coletiva dominante, sem deixar de considerar a multiplicidade de estratos do tempo (KOSELLECK, 2006), o que faz com que se considere não apenas a linearidade ou a circularidade do tempo, mas as múltiplas camadas que coexistem no momento histórico considerado.

Por outro lado, há que remarcar ainda que as temporalidades dominantes nas épocas são construídas numa duração mais longa, num jogo de rupturas e continuidades. Podemos exemplificar essa questão com a categoria aceleração. Desde a virada do século XIX havia na sociedade brasileira, por exemplo, a percepção e a vivência de um tempo que se acelerava frente às tecnologias que invadiam o cotidiano. Se as inovações 
tecnológicas e comunicacionais davam a impressão que o tempo corria mais rápido, os próprios artefatos tecnológicos (máquinas impressoras, máquinas de compor, máquinas de escrever, etc.) permitiram a aceleração do tempo de produção do jornalismo, mudando as lógicas temporais em vários níveis (no cotidiano da profissão, no tempo "levado para contar"3 uma história, no tempo desprendido pelo leitor para se apoderar da narrativa, etc.). Era, sem dúvida, um tempo que andava mais rápido em relação às experiências anteriores.

Essa mesma aceleração se exacerbou ao longo do século XX, construindo o tempo de turbilhão como o que é percebido por cada um de nós na contemporaneidade. Se, por um lado, o progresso era a chave do tempo linear dominante na virada do século XIX para o XX, e que foi abandonado ao longo do percurso, havia igualmente outras camadas temporais que coexistiam e que permaneceram durando: o apanágio da tecnologia como inserção de um novo tempo é apenas uma delas.

Portanto, a coexistência dos estratos do tempo não invalida que possamos dizer que exista uma certa "ordem do tempo", tal como conceitua Pomian (1984), ou seja, a prevalência de uma determinada arquitetura temporal decorrente das experiências humanas, das crenças e das representações. Esse predomínio não nega, entretanto, outras percepções do tempo no mesmo momento e contexto histórico. Há sempre múltiplas percepções, que coexistem, se chocam, se aproximam, se distanciam e se misturam. Como diz Koselleck (2006, p. 320), no decurso único do tempo há a existência de um “dinamismo de estratos múltiplos vividos simultaneamente". Portanto, na avaliação do teórico alemão, a ideia de tempo linear e de tempo circular, recorrentes na sequência história, são insuficientes para a compreensão da questão temporal.

Entre as experiências que transpassam o cotidiano, o tempo midiático é, certamente, dominante: o tempo de produção da mídia; o tempo do usuário diante daquelas narrativas; o tempo transformado do mundo pela ação de se viver na mídia. $O$ tempo dos múltiplos frames narrativos presentes nos gêneros midiáticos; o tempo em relação ou solitário que se estabelece na maneira como se conecta com as materialidades midiáticas; o tempo de ação e de reação; o tempo da indiferença diante de um mundo que passa rapidamente perante os nossos olhos.

Em relação ao que poderíamos chamar as tramas temporais midiáticas, destacaremos dois aspectos: a relação do jornalismo com o tempo como definidora da

\footnotetext{
${ }^{3}$ Estamos aqui fazendo alusão à expressão utilizada por Ricoeur (1997), no clássico texto Mundo do texto e mundo do leitor.
} 
própria essência da atividade jornalística e a maneira como a questão da temporalidade emerge da questão narrativa. A narrativa midiática, além de instaurar os múltiplos tempos na ação de contar uma história - o tempo contado, o tempo levado para contar e o tempo apropriado ou reconfigurado no mundo, tal como enfatiza Ricoeur (1997) - possui uma relação particular com o presente, o passado e o futuro, como já destacamos.

No que diz respeito especificamente ao jornalismo há que se ressaltar que desde o início dos anos 2000, alguns pesquisadores brasileiros vêm se dedicando a explorar a complexa relação do jornalismo com as aporias da temporalidade (ANTUNES, 2007; FRANCISCATO, 2005; MATHEUS, 2010; RÊGO, 2014, entre outros). O vínculo com o passado e com a perspectiva histórica também tem sido objeto de reflexões, anunciando uma dupla articulação temporal presente nas narrativas jornalísticas: ao mesmo tempo em que atualizam o tempo, evocam o passado, fazendo diversos usos dos tempos idos (BARBOSA, 2009, 2017).

No caso brasileiro, o jornalismo se constituiu, no século $\mathrm{XX}$, como instância legítima para contar o mundo a partir de pressupostos que entrelaçaram o campo político e literário e sua autonomização profissional, num lento processo que se desenrolou ao longo de todo o século XX. Isso se deu exatamente a partir da constituição de discursividades próprias, cujas premissas se fizeram a partir da sua autonomização em relação a esses dois campos (BARBOSA, 2007a; RIBEIRO, 2007).

Além dessa constatação, há que se referir aos vínculos que o jornalismo brasileiro sempre guardou com o campo político - não querendo assumir o papel de "cães de guarda" em relação ao poder, papel importante e decisivo para conformação jornalística norte-americana, por exemplo -, estreitando seus vínculos, muitas vezes de maneira escusa, com a política. Ao assumir papéis determinantes na história política do país (como, por exemplo, no episódio que culminou com o suicídio do Presidente Vargas; na aceitação pacífica e, mais do que isso, muitas vezes parceira ou silenciosa em relação aos desmandos durante a ditadura militar; no apoio incondicional da chamada grande mídia ao impeachment da presidente Dilma Roussef, apenas para citar alguns momentos), o jornalismo no Brasil caracteriza-se por estar atrelado aos liames do chamado pensamento conservador que domina o cenário institucional e ideológico desde os anos 1920. Esse pensamento, herança do autoritarismo europeu com nuances de ampliação do escopo reacionário em função da própria historicidade do país - que naturalizou durante séculos, por exemplo, o processo de escravização humana -, domina a configuração midiática, mesmo nos cenários mais contemporâneos nos quais a sensação de pluralidade de ideias 
se instaura, sobretudo, diante da promessa das novas mídias e plataformas que emergem nos ambientes digitais. Mas que, na prática, reproduzem e exacerbam a lógica do pensamento único.

Por outro lado, a autonomização em relação à literatura - indispensável na configuração de um discurso que buscava referencialidade em relação às verdades do mundo e que deveria conter uma narrativa que espelhasse um mundo real e único para o público - foi a pedra de toque do chamado processo de modernização, num longo movimento que se iniciou no começo do século XX e teve o seu momento emblemático na década de 1950.

As transformações por que passa o jornalismo no século XXI, rotuladas por alguns autores como crise do jornalismo, causada pela perda do domínio sobre a produção de registros sobre o que se passa no mundo, são tributárias também da transformação da marcação do tempo nas suas narrativas. Nesse cenário, a inclusão de notícias ligeiras, em contraposição às grandes reportagens, causa uma irreparável incerteza em relação ao gênero que foi considerado modelo e síntese da atuação jornalística (BERGAMO, 2011; MORAES, 2017), produzindo reconfigurações, por exemplo, nas identidades jornalísticas.

Há que se ter em mente ainda o embaralhamento de fronteiras entre opinião e informação no jornalismo contemporâneo, próprio de uma época em que o desejo de opinião se contrapõe ao mito da imparcialidade do jornalismo. Assim, se a essência do jornalismo moderno formou-se a partir da separação entre o domínio opinativo e o informativo, observamos, cada vez mais, uma indistinção de fronteiras entre esses dois lugares de fala.

Criado como instituição basilar da modernidade, o jornalismo se constituiu, prioritariamente, a partir de dois regimes: o de temporalidade e o de verdade, que passaram a guiar suas práticas, implicando na apropriação de figuras de historicidade. Mas na contemporaneidade, o tempo emblema do jornalismo não é mais o presente, mas o futuro (RÊGO, 2018) $)^{4}$.

Ao analisar a narrativa jornalística a partir dos jogos temporais, Rêgo (2018), por exemplo, afirma o primado do futuro como produto da narrativa jornalística, já que a

\footnotetext{
${ }^{4}$ No artigo em que defende essa tese, Rêgo (2018) afirma que o tempo primevo do jornalismo nunca foi o presente, pois como esclarece Benveniste (apud RÊGO, 2018, p. 153), o presente significa "o que está a minha frente", sendo, portanto, o iminente.
} 
busca da novidade faz com que a experiência narrada se projete do presente até o futuro. A simultaneidade do presente em sua narrativa, pontua a autora, é meramente uma ilusão.

Podemos mesmo afirmar que o desejo de futuro é tão premente no jornalismo hoje, que o presente se esfacela nas suas narrativas que, se atualizando sem cessar, querem reproduzir uma espécie de ultra-atualidade. O tempo linear do jornalismo parece ter sido substituído pelo tempo espiralado que demarca o presente-futuro como moto contínuo.

Se o tempo representado do jornalismo é governado pela impossibilidade do presente, há muitas outras tramas temporais nos seus modos narrativos e produtivos. Há que se acrescentar, por exemplo, os múltiplos tempos dos processos produtivos que se transformam de maneira proeminente frente às práticas do mundo digital; os tempos de duração do próprio produto midiático (jornal, revista, televisão, internet e o tempo diverso de cada uma das editorias das publicações); o tempo da mídia como uma espécie de relógio midiático em função da sua periodicidade (e o embaralhamento dos tempos, mais uma vez, diante das possibilidades digitais que permitem a volta na narrativa, a sua retomada depois de sua emissão primeira, a qualquer tempo e em qualquer lugar, ao simples toque digital); o tempo de apropriação do público em função de uma enorme pluralidade de parâmetros (entre elas, as expectativas em função do reconhecimento dos gêneros); a maneira como o público se coloca diante da narrativa produzida; ou seja, "o tempo contado, o tempo levado para contar" (RICOEUR, 1997), os tempos do leitor e de suas leituras, aqui qualificadas num sentido mais amplo, percebendo leituras como textualidades múltiplas que frequentam o mundo do público.

Há ainda que se referir à noção de encurtamento temporal, que é outra marca narrativa do jornalismo, sempre na busca de uma atualidade absoluta ou uma ultraatualidade. Desde meados do século XIX, quando notícia passa ser cada vez mais vinculada à ideia de novidade, abandonando a noção de esclarecimento que a definia anteriormente, o encurtamento do tempo para a divulgação das informações do mundo passa a ser buscado de maneira incessante. Aliás, as tecnologias colocadas à disposição do jornalismo naquele momento (das quais o telégrafo é a mais evidente) tornaram possível que a atualidade deixasse de ser medida por meses entre o fato e sua publicação e passasse a ser governada pelos dias. No século XIX, evidentemente, as temporalidades eram das guerras que duravam séculos, de viagens que duravam meses. Portanto, mesmo a noção de encurtamento temporal é dependente dos regimes temporais de cada época. Assim, durante muito tempo no jornalismo o ontem foi, de fato, o mais atual. 
Hoje, observamos nas narrativas jornalísticas nos meios digitais um apagamento progressivo dos códigos temporais ou a pouca importância dada a eles, o que faz com que mesmo republicando notícias já divulgadas, essas passem a ser notícias daquele minuto (o minuto da leitura). Esse apagamento referenda o pressuposto de que, não importa a data do seu aparecimento, essas notícias divulgadas, em função das possibilidades das plataformas digitais, são sempre as mais instantâneas, mesmo que, de fato, não se configurem como tal.

\section{E o passado?}

A proeminência do presente e a lógica do presentismo, que são dominantes nos tempos midiáticos, não significam a obliteração do passado. Há muitas apropriações do passado nas narrativas midiáticas, que aparecem caracterizadas de maneira particular, já que num tempo sem espessura é preciso ter a ilusão de preservá-lo, uma vez que sem memória espontânea torna-se necessário registrar a própria vida em profusão e relembrar o passado em momentos precisos.

No processo de reconstrução do passado como história, os meios de comunicação possuem lugar estratégico, na medida em que se apregoam como produtores de uma história imediata e reconstrutores da integralidade do passado.

Nas tramas narrativas midiáticas observamos, assim, uma dupla prevalência de caracterizar o tempo: o uso particular do passado e, concomitantemente, a construção de um presente estendido, que inclui o futuro. Em relação aos usos do passado realizados pelos meios de comunicação, observa-se que as suas narrativas já possuem o desejo de futuro e são construídas visando a sua permanência e reutilização em outro momento. A mídia produz narrativas como arquivos da e para a história. Em função disso proliferam também as referências ao passado: o passado transformado em discurso comum, inclusive do ponto de vista de uma memória histórica partilhada; ao passado de sua própria história; e ao passado como utopia midiática reconstruindo de maneira idílica os tempos de outrora (BARBOSA, 2017) .

Como bem remarca Sarlo (2005), há coincidências entre a aceleração do tempo e a vocação memorialística. Se por um lado a aceleração produz um vazio de passado, as operações de memória tentam compensar. Trata-se, segundo ela, de uma cultura, ao mesmo tempo, da velocidade e da nostalgia, do esquecimento e das comemorações.

Por isso não causa estranhamento a profusão de narrativas nos meios de comunicação que trazem rememorações do passado, projetos que comemoram sem cessar 
múltiplas datas. Há que se levar em conta que os meios de comunicação não se constroem apenas como documentos para a história, mas já produzem suas narrativas visando a sua reapropriação futura, sendo, antes de tudo, documentos de memória.

Mas, afinal, o que é o passado? Podemos chamar de passado a matéria da história, isto é, um tempo que existiu e que por meio dos rastros e restos (HELLER, 1993; RICOEUR, 2007) podemos ver indícios de sua presença. A disciplina histórica, ao se ocupar das ações dos homens no tempo e não estrito senso do passado, produz como matéria essencial para a sua inscrição o tempo calendário. Através dele determinamos as épocas, as fases, as datas numa linha artificial que passa a ser sucessiva e datada (POMIAN, 1984; RICOEUR, 2007). Mas, cada época histórica também tem uma forma particular de experimentar o passado.

Ao se experimentar hoje o tempo como algo sempre novo, inédito, em que alterações cada vez mais rápidas exigem adaptações também muito mais rápidas, se está, na verdade, alargando o presente e nele introduzindo o futuro. O presente passa a ser não apenas o agora - isto é, um tempo que se diferencia do que já terminou, o passado - mas também o que ainda está por vir. Constrói-se, assim, uma linha artificial e extremamente tênue que divide aquilo que já aconteceu (o passado) daquilo que se está vivendo, o presente sem fim. Por outro lado, há que se remarcar que num mundo marcado pela construção de um futuro que começa agora, o passado também ressignifica o presente. Nessa perspectiva, há que distinguir um tempo radicalmente novo em relação a um presente que dura, pois nele inclui o futuro. É dessa forma que também o passado passa a ser um tempo novo.

Tão novo que pode ser descartado continuamente. Na contemporaneidade, a aceleração do ritmo da vida e da experiência impedem ações de pequenos retornos como, por exemplo, a volta à leitura ao que já tomamos conhecimento nas redes virtuais, pois temos a ilusão de que esses arquivos presentes estarão sempre à nossa disposição. Flagrante ilusão. O apagamento frenético e sucessivo dos arquivos do mundo digital contribui igualmente para a promoção da amnésia contemporânea.

Se o mundo parece, aos olhares mais inocentes, estar à nossa disposição como num passe de mágica, a lógica comum ao mundo digital é a do esquecimento contínuo, que se manifesta no apagamento incessante dos rastros digitais. $\mathrm{Na}$ medida em que o futuro já está incluído no presente, a pergunta que deixamos como trama final neste texto é: que rastros estarão disponíveis nas décadas que estão por vir sobre este nosso presente estendido que produz o futuro como esquecimento? 


\section{Referências}

ANTUNES, Elton. Videntes imprevidentes: temporalidade e modos de construção de sentido de atualidade em jornais impressos diários. 2007. 317 f. Tese (Doutorado em Comunicação) - Programa de Pós-Graduação em Comunicação e Cultura Contemporânea, Universidade Federal da Bahia, Salvador, 2007. Disponível em: https://repositorio.ufba.br/ri/handle/ri/11295. Acesso em: 23 jan. 2019.

BARBOSA, Marialva. Comunicação e história: presente e passado em atos narrativos. Comunicação, Mídia e Consumo, São Paulo, v. 6, p. 11-27, jul. 2009. Disponível em: http://revistacmc.espm.br/index.php/revistacmc/article/view/154.

BARBOSA, Marialva. História cultural da imprensa: 1900-2000. Rio de Janeiro: MauadX, 2007a.

BARBOSA, Marialva. Meios de comunicação, memória e tempo: a construção da redescoberta do Brasil. In: HERSCHMANN, Micael; PEREIRA, Carlos Alberto Messeder (org.). Mídia, memória e celebridades: estratégias narrativas em contextos de alta visibilidade. Rio de Janeiro: E-papers, 2003. v. 1, p. 112-134.

BARBOSA, Marialva. Percursos do olhar: comunicação, narrativa e memória. Niterói: EdUFF, 2007b.

BARBOSA, Marialva. Tempo, acontecimento e celebração: a construção dos 500 anos do Brasil nos gestos comemorativos da TV Globo. Comunicação e Sociedade, São Paulo, v. 33, p. 67-88, 2000a.

BARBOSA, Marialva. Tempo, tempo histórico e tempo midiático: interrelações. In: MUSSE, Christina Ferraz; VARGAS, Herom; NICOLAU, Marcos (org.).

Comunicação, mídias e temporalidades. Salvador: EDUFBA, 2017. p. 19-36.

BARBOSA, Marialva. Temporalidade mundo e temporalidades particulares: o dilema da contemporaneidade. Anuário Unesco/Umesp de Comunicação Regional, v. 3, p. $11-24,2000 b$.

BARBOSA, Marialva. Temporalidade: uma questão midiática. Margem, São Paulo, v. 1, p. 177-190, 1999.

BASCHET, Jérôme. L'histoire face au présent perpétuel, quelques remarques sur la relation passé/futur. In: HARTOG, François; REVEL, Jacques (dir.). Les usages politiques du passé. Paris: EHESS, 2001. p. 55-74.

BERGAMO, Alexandre. Reportagem, memória e história no jornalismo brasileiro. Mana, v. 2, n. 17, p. 233-269, 2011. Disponível em: http://www.scielo.br/pdf/mana/v17n2/a01v17n2.pdf. Acesso em: 23 jan. 2019.

CALVINO, Italo. Leçons américaines: aide-mémoire pour le prochain millénaire. Paris: Gallimard, 1989. 
CHESNEAUX, Jean. Habiter le temps. Paris: Bayard, 1996.

FRANCISCATO, Carlos Eduardo. A fabricação do presente: como o jornalismo reformulou a experiência do tempo nas sociedades ocidentais. São Cristóvão: Ed. UFS; Aracaju: Fundação Oviêdo Teixeira, 2005.

HARTOG, François. Regimes de historicidade: presentismo e experiências do tempo. Belo Horizonte: Autêntica, 2014.

HELLER, Agnes. Uma teoria da História. Rio de Janeiro: Civilização Brasileira, 1993.

KOSELLECK, Reinhart. Futuro passado: contribuição à semântica dos tempos históricos. Rio de Janeiro: Contraponto: Ed. PUC, 2006.

MATHEUS, Letícia Cantarela. Comunicação, tempo, história: tecendo o cotidiano em fios jornalístico. 2010. Tese (Doutorado em Comunicação) - Programa de PósGraduação em Comunicação, Universidade Federal Fluminense, Niterói, 2010. Disponível em: https://app.uff.br/riuff/handle/1/4029?mode=full. Acesso em: 18 jan. 2019.

MORAES, Vaniucha de. A elite dos jornalistas brasileiros: estratégias de legitimação e simbolização entre o período ditatorial e os anos pós-redemocratização. 2017. Tese (Doutorado em Sociologia e Política) - Programa de Pós-Graduação em Sociologia e Ciência Política, Universidade Federal de Santa Catarina, Florianópolis, 2017.

Disponível em: https://repositorio.ufsc.br/handle/123456789/188202. Acesso em: 18 jan. 2019

POMIAN, Krzysztof. L’ordre du temps. Paris: Gallimard, 1984.

RÊGO, Ana Regina. Articulação temporal e essência narrativa: o jornalismo para além do tempo presente. Contracampo, Niterói, v. 37, n. 3, p. 149-168, 2018. Disponível em: http://periodicos.uff.br/contracampo/article/view/19453. Acesso em: 17 jan 2019.

RÊGO, Ana Regina. Jornalismo: temporalidades, ética e memória. In: RÊGO, Ana Regina; QUEIROZ, Teresinha; MIRANDA, Marcela (org.). Narrativas do jornalismo e narrativas da história. Porto: Mídia XXI, 2014. p. 33-56.

RIBEIRO, Ana Paula Goulart. Imprensa e história no Rio de Janeiro dos anos 50. Rio de Janeiro: E-papers, 2007.

RICOEUR, Paul. A memória, a história e o esquecimento. Campinas: UNICAMP, 2007.

RICOEUR, Paul. Tempo e narrativa. Campinas: Papirus, 1997. v. 3.

SARLO, Beatriz. Tempo presente: notas sobre a mudança de uma cultura. Rio de Janeiro: J. Olympio, 2005. 
Submetido em: 23.08.2019

Aprovado em: 30.10.2019 